7. E. R. Lorch: The Cauchy-Schwarz inequality and self-adjoint spaces. (Abstract 51-3-64-t.)

\author{
A. C. Schaeffer, \\ Associate Secretary
}

\title{
REPORT OF THE MEETING OF THE COUNCIL OF THE SOCIETY IN NEW YORK CITY ON APRIL 28, 1945
}

A meeting of the Council of the Society was held in the Men's Faculty Club at Columbia University at 1:30 P.M. on Saturday, April 28, 1945. The following members of the Council were present: A. A. Albert, Garrett Birkhoff, S. S. Cairns, Richard Courant, Arnold Dresden, B. P. Gill, M. R. Hestenes, T. R. Hollcroft, Harold Hotelling, Saunders MacLane, J. F. Ritt, P. A. Smith, I. S. Sokolnikoff, J. D. Tamarkin, Hassler Whitney, and the Secretary.

Certain papers submitted for presentation at various meetings of the Society were read by title at the meeting of the Council; titles and cross references to the abstracts of these papers appear at the end of this report.

The Secretary announced the election of the following ten persons to ordinary membership in the Society:

Mr. Silvio Aurora, Columbia University;

Professor Harold Frederick Bright, University of Rochester;

Miss Helen M. Clark, Northwestern University;

Dr. Vincent Frederick Cowling, Rice Institute;

Mrs. Anne Carples Davis, Seaman Second Class, U.S.N.R.;

Mr. Richard Latter, Lieutenant, U.S.N.R.;

Mr. Douglas Blakeshaw Netherwood, Captain, A.U.S.;

Mr. Joseph Thomas Olsztyn, Private, U.S.A.;

Mr. Clarence A. Phillips, University of Illinois;

Mr. Marlow Canon Sholander, Brown University.

The Department of Mathematics of the University of Oregon was elected to institutional contributing membership.

The following appointment by the President was reported: as a Committee to Select Gibbs Lecturers for 1946 and 1947, Professors L. M. Graves (Chairman), G. A. Hedlund, and S. S. Wilks.

It was reported that the Board of Trustees had approved the recommendation of the Council that a catalogue of the Society library be published during 1945 and that the Board had appropriated $\$ 2500$ for this purpose. 
The Secretary called the attention of the Council to the following policy which has been followed in recent years: if both husband and wife are members of the Society, one is allowed to receive the Transactions, instead of the Bulletin, as one of the privileges of membership.

Professor Oswald Veblen was appointed representative of the Society in the Division of Physical Sciences of the National Research Council for a period of three years, beginning July, 1945.

The Council authorized the appointment by the President of a committee to study the problem of aid to devastated libraries.

Secretary Kline reported for the War Policy Committee as follows:

1. A subcommittee of the War Policy Committee has been appointed to study the relation of mathematics to the compulsory military training program being considered by the government; this subcommittee consists of Professors W. L. Hart (Chairman), Saunders MacLane, and C. B. Morrey, Jr. The final report of this subcommittee will probably be offered for publication in Science as well as in the mathematical journals.

2. The Rockefeller Foundation has extended its second grant for the work of the War Policy Committee from December 31, 1944, to September 30,1945 , and has made a grant of $\$ 1,000$ for the period January 1-September 30, 1945.

3. The Subcommittee to Advise the Examinations Staff of the Armed Forces Institute (Professor W. T. Reid, Chairman) has been discharged with thanks. A general report on the activities of this subcommittee appeared in the March, 1945, issue of The American Mathematical Monthly. Examinations have been prepared in algebra, plane trigonometry, analytic geometry, differential and integral calculus; these are to be standardized under a project which is being undertaken jointly by the War Department and the Cooperative Test Service of the American Council on Education.

4. Since the work of the Subcommittee on War Training Programs (Professor W. L. Hart, Chairman) has been finished, this subcommittee has been discharged with thanks.

5. The Committee recommended that the Presidents and Secretaries of the Society and Association make application to the War Committee on Conventions for permission to hold the 1945 Summer Meeting in Montreal, Canada.

6. The Committee approved the bill calling for the assignment of students to a national scientific education program.

7. The Committee has studied the problem of the place of the National Roster of Scientific and Specialized Personnel in the postwar 
period and has made recommendations to a national committee appointed to study this problem. In this connection the Secretary called attention to the lists of publications maintained in his office. These are complete lists of publications for all persons who have received the doctorate in mathematics in America. The lists for those who received the doctorate abroad are complete for the period subsequent to their appointments at American institutions.

The Council approved with certain changes a proposed bill to authorize the assignment of persons to a national scientific program instead of to service in the armed forces, in order to make possible the education and training of scientists to meet essential needs.

The Secretary reported that application had been made to the War Committee on Conventions for permission to hold a meeting of the Society in Montreal at the conclusion of the Canadian Mathematical Congress. (The regulations of the Office of Defense Transportation require that permission be secured, even though meetings are scheduled outside continental United States.) The President and Secretary were empowered to take action regarding the 1945 Summer Meeting in light of the ruling of the Office of Defense Transportation.

Titles and cross references to the papers read at the Council meeting follow below. Mr. DeBaggis was introduced by Professor Menger.

1. R. P. Agnew: Spans of translations of peak functions. (Abstract 51-5-84-t.)

2. R. P. Boas: Fundamental sets of analytic functions. (Abstract 515-85-t.)

3. H. F. DeBaggis: A simplified projective theory of order and parallelism in the hyperbolic plane. (Abstract 51-5-97-t.)

4. Herbert Federer: Coincidence functions and their integrals. (Abstract 51-7-113-t.)

5. Evelyn Frank: Corresponding type continued fractions. (Abstract 51-7-114-t.)

6. A. P. Hillman: On identities for differential polynomials. (Abstract 51-5-73-t.)

7. A. P. Hillman: Theorems obtained from the Nezton polygon process for differential polynomials. (Abstract 51-5-74-t.)

8. L. K. Hua: Geometries of matrices. I. Generalizations of von Staudt's theorem. (Abstract 51-5-95-t.)

9. L. K. Hua: Geometries of matrices. $\mathrm{I}_{1}$. Arithmetical construction. (Abstract 51-5-96-t.)

10. S. B. Jackson: The four-vertex theorem for surfaces of constant curvature. (Abstract 51-3-68-t.) 
11. R. E. Johnson: Systems of finite linear equations. (Abstract 513-55-t.)

12. G. K. Kalisch: A spectral theory for symmetric operators over generalized Hilbert spaces. (Abstract 51-5-76-t.)

13. Irving Kaplansky: $A$ note on groups without isomorphic subgroups. (Abstract 51-5-78-t.)

14. Irving Kaplansky: Maximal fields with valuations. II. (Abstract 51-5-79-t.)

15. Irving Kaplansky: The asymptotic distribution of runs of consecutive elements. (Abstract 51-5-101-t.)

16. J. N. B. Livingood: $A$ partition function with the prime modulus $p>3$. (Abstract 51-3-56-t.)

17. N. H. McCoy: Subdirectly irreducible commutative rings. (Abstract 51-5-80-t.)

18. Morris Marden: $A$ note on the zeros of the sections of a partial fraction. (Abstract 51-5-88-t.)

19. Karl Menger: A projective definition of hyperbolic congruency independent of parallelism. (Abstract 51-5-99-t.)

20. Karl Menger: A projective definition of hyperbolic perpendicularity without reference to parallelism. (Abstract 51-5-98-t.)

21. L. J. Mordell: Further contributions to the geometry of numbers for non-convex regions. (Abstract 51-7-108-t.)

22. V. C. Poor: On the Hamilton differential. (Abstract 51-7-121-t.)

23. A. R. Schweitzer: Functional relations valid in the domains of abstract groups and Grassmann's space analyais. III. (Abstract 51-590-t.)

24. Otto Szász: On some summability methods with triangular matrix. (Abstract 51-5-91-t.)

25. H. S. Wall: Polynomials with real coefficients whose zeros have negative real parts. (Abstract 51-3-60-t.)

26. F. T. Wang: Strong summability of Fourier series. (Abstract 515-92-t.)

27. F. T. Wang: Tauberian theorem of oscillating series. (Abstract 51-5-93-t.)

28. J. E. Wilkins: A generalization of the Euler $\phi$-function. (Abstract 51-5-83-t.)

J. R. KLINE, Secretary 